\title{
A CONSCIÊNCIA COMO UMA PERCEPÇÃO DO MENTAL E O ESTATUTO DOS FENÔMENOS MENTAIS INCONSCIENTES NA PERSPECIIVA DE DAVID ARMSTRONG ${ }^{1}$
}

\author{
CONSCIOUSNESS AS A PERCEPTION OF THE MENTAL
}

AND THE STATUS OF UNCONSCIOUS MENTAL PHENOMENA

IN DAVID ARMSTRONG'S VIEW

\author{
TÁRIK DE ATHAYde PRATA ${ }^{2}$ \\ Universidade Federal de Pernambuco (UFPE) - Brasil \\ tarik.de_athayde_prata@alumni.uni-heidelberg.de
}

\begin{abstract}
RESUMO: O artigo examina a teoria de David Armstrong sobre a consciência e sua concepção do inconsciente. Após uma discussão do caráter anti-cartesiano dessa teoria (seção 1), são discutidas as noções de consciência mínima e consciência perceptiva (seção 2), bem como o conceito de consciência introspectiva, que é o mais importante para Armstrong (seção 3). A conclusão é que, apesar do valor explicativo dos seus conceitos de consciência, Armstrong defende uma perspectiva insatisfatória a respeito do inconsciente, pois essa perspectiva não dá conta da real influência do inconsciente em nossa vida mental (seção 4).
\end{abstract}

PALAVRAS-CHAVE: Consciência. Inconsciente. Percepção. Introspecção.

ABSTRACT: This paper examines David Armstrong's theory of consciousness and his view of the unconscious. After a discussion of the anti-Cartesian character of this theory (section 1), the concepts of minimal consciousness and perceptive consciousness are discussed (section 2), as well as the concept of introspective consciousness, which is the most important for Armstrong (section 3). The conclusion is that, despite the explanatory value of his concepts of consciousness, Armstrong holds an unsatisfactory view about the unconscious, since he does not account for its real influence on our mental lives (section 4).

KEYWORDS: Consciousness. Unconscious. Perception. Introspection.

\section{INIRODUÇÃO}

Durante longo tempo, as diversas noções associadas à palavra "consciência" desfrutaram de um lugar de destaque nas concepções filosóficas (e científicas) sobre a mente. De acordo com o influente filósofo alemão Franz Brentano (18381917), ele mesmo um opositor da ideia de inconsciente, alguns milênios se

\footnotetext{
${ }^{1} \mathrm{O}$ presente trabalho foi produzido no âmbito do projeto de pesquisa "Concepções teóricas da consciência e o problema dos fenômenos mentais inconscientes", registrado no Programa de PósGraduação em Filosofia da UFPE. Gostaria de agradecer aos pareceristas anônimos da revista Sofia, por suas importantes observações e sugestões.

${ }^{2}$ Departamento de Filosofia da Universidade Federal de Pernambuco (UFPE).
} 
passaram na história da Filosofia antes que aparecesse um filósofo que defendesse a existência de fenômenos mentais inconscientes (cf. BRENTANO, 1924, p. 144; BRENTANO, 1995, p. 103), ${ }^{3}$ e não se pode esquecer que René Descartes (15961650), o pensador de maior influência na reflexão filosófica sobre os fenômenos mentais, ${ }^{4}$ caracterizava o pensamento (visto por ele como a essência da alma) como "tudo quanto está de tal modo em nós que somos imediatamente conscientes [CONSCI]" (DESCARTES, 1979, p. 169 [AT, VII, p. 160; AT, IX, p. 124]5).

Entretanto, por volta da primeira metade do século XX houve uma inversão nesse cenário, na medida em que a importância dos fenômenos inconscientes aumentou de maneira progressiva, e o principal responsável por essa mudança foi um aluno de Brentano (cf. SCHELLENBACHER, 2011; CATALDO-MARIA \& WINOGRAD, 2013), o médico e criador da psicanálise Sigmund Freud (1856-1939). Como coloca John Searle, se as gerações passadas tendiam a ver a noção de consciência como não problemática, e a noção de inconsciente como misteriosa, ou até autocontraditória, nós invertemos os papéis, pois "depois de Freud, nós invocamos rotineiramente fenômenos mentais inconscientes para explicar os seres humanos, e achamos a noção de consciência misteriosa, e talvez mesmo anticientífica" (SEARLE, 1992, p. 151; SEARLE, 1997, p. 218). De fato, Freud insurgiu-se contra a identificação do domínio psíquico com a consciência, e defendeu que os processos mentais são, fundamentalmente, inconscientes. ${ }^{6}$

Mas o fato de que a consciência, hoje em dia, não é mais vista de modo tão óbvio como o fundamento da mente não significa que ela não seja um importante tema de investigação (Não se pode esquecer, aliás, que o próprio Freud elaborou ideias a respeito da consciência - Cf. CAROPRESSO, 2009). Na tradição da filosofia analítica, por exemplo, uma das mais influentes na contemporaneidade, ${ }^{7}$ a temática da consciência adquiriu um lugar central, após décadas de negligência, causada pela influência do positivismo lógico e de várias outras concepções fisicalistas sobre a mente (cf. SEARLE, 1992, pp. 02-05; SEARLE, 1997, p. 08-13). Dentro da tradição analítica, se constituíram várias correntes de pensamento a respeito da

\footnotetext{
3 "Até muito recentemente na história da ciência e da filosofia, a vida mental era considerada inteiramente, ou principalmente, consciente em sua natureza" (BARGH \& MORSELLA, 2008, p. 73). As citações em língua estrangeira foram traduzidas para o português pelo autor do presente trabalho.

4 "Representação e consciência são consideradas ainda hoje - apesar de Wittgenstein - como as características decisivas do mental. Não se pode encontrar um único homem que tenha sido mais influente para esse tipo de caracterização do mental do que Descartes. Suas teorias sobre esses assuntos não são aceitas por quase ninguém e menos ainda são os que as compreendem. Entretanto, o modo como ele trata filosoficamente esses temas é até hoje inconscientemente imitado por muitos" (KEMMERLING, 2005, p. 09).

${ }^{5}$ Entre colchetes estão indicadas as referências ao volume VII (latim) e ao volume IX (francês) da edição das obras de Descartes organizada por Charles Adam e Paul Tannery (AT).

6 "A primeira dessas declarações perturbadoras da psicanálise diz que os processos psíquicos são em si e para si inconscientes, e que conscientes são apenas atos isolados e partes do todo da vida psíquica. [...] [A psicanálise] não pode aceitar a identidade do consciente com o psíquico. Sua definição do psíquico diz que seriam processos do tipo do sentir, do pensar, do querer, e ela tem que defender a existência de pensamentos e vontades inconscientes." (FREUD, 1982, p. 47).

${ }^{7}$ Como coloca Habermas: "a filosofia analítica adquire, nas décadas após a segunda guerra mundial, a sua posição imperial, a qual continua se mantendo até hoje através de Quine e Davidson" (HABERMAS, 1990, p. 12). O texto de Habermas foi publicado, originalmente, em 1988.
} 
consciência (cf. VAN GULICK, 2012) que, no meu modo de entender, oferecem preciosas contribuições para a devida compreensão desse tema.

O caso é que, se podemos pensar a consciência como uma entidade ou como uma faculdade (que podemos designar com o nome abstrato "consciência"), podemos também pensá-la como algum tipo de propriedade, que pode ser designada pelo predicado monádico “... é consciente”, ou pelo predicado diádico “... é consciente de ..." (cf. GENNARO, 1996, p. 03). E se a consciência é pensada como uma propriedade pertencente a certos estados mentais (que são, portanto, estados mentais conscientes), torna-se importante explicar em que essa propriedade consiste ${ }^{8}$ e como ela surge, ou seja, explicar como estados mentais se tornam estados conscientes.

Essa formulação do problema já sugere que a consciência está sendo concebida como uma propriedade não essencial dos estados mentais que, eventualmente, a possuem; ou seja, uma propriedade sem a qual os estados mentais podem continuar a existir (de forma inconsciente). Uma concepção como essa, ou seja, uma concepção da consciência como uma propriedade extrínseca de certos estados mentais, articula-se com a derrocada do cartesianismo no campo das investigações sobre a consciência, ao mesmo tempo em que mostra a consciência como um tema importante de investigação, pois a questão a respeito de como essa propriedade surge é extremamente relevante para a compreensão de nossa vida psíquica. Em outras palavras: do fato de a consciência não ser uma propriedade essencial para a existência dos fenômenos mentais, de maneira que ela não seja o fundamento da mente, não se segue que a consciência não seja um tema importante de investigação, já que ela desempenha um papel importante em nossa existência psicológica.

Uma visão desse tipo a respeito da consciência (ou seja, que a vê como uma propriedade extrínseca) é o que encontramos nas chamadas "teorias de ordem superior" (higher-order theories), isto é, teorias segundo as quais a consciência como característica de um fenômeno mental decorre de seu monitoramento por um outro fenômeno mental, que é acerca do primeiro (GENNARO, 2004, p. 01-02; VAN GULICK, 2004, p. 68; VAN GULICK, 2012, pp. 47-49). E um dos principais expoentes das teorias de ordem superior foi o filósofo australiano David Armstrong (1926-2014), um dos maiores nomes da filosofia analítica no século XX, e autor cujas reflexões sobre a consciência tiveram grande impacto na filosofia da mente.

Armstrong via a consciência de estados mentais (no sentido mais interessante da palavra "consciência") como decorrente de uma percepção do mental, ${ }^{9}$ um ponto de vista que, como será discutido a seguir, se coaduna de maneira simples e direta com a visão de que existem fenômenos mentais

\footnotetext{
${ }^{8}$ Conforme será explicitado a seguir, de acordo com as teorias de ordem superior, um estado mental possui a propriedade de ser consciente quando nós estamos conscientes dele (de modo que se trata de uma propriedade relacional).

9 A percepção (interna) de um fenômeno mental é uma representação meta-psicológica no sentido de que essa percepção (que é um fenômeno psicológico) é a respeito de um outro fenômeno psicológico (cf. GENNARO, 2004, p. 01). O prefixo "meta" indica que um fenômeno psíquico (a percepção interna) se dirige a outro fenômeno psíquico (seja ele uma percepção externa, uma crença, um desejo, etc.).
} 
inconscientes (cf. ARMSTRONG, 1997, p. 724). De acordo com ele: "consciência não é mais do que a ciência ${ }^{10}$ (percepção) dos estados mentais internos pela pessoa que possui esses estados mentais. Se é assim, então a consciência é simplesmente um outro estado mental, dirigido aos estados internos originais" (ARMSTRONG, 1968, p. 94 - grifo acrescentado). É justamente nesse sentido, de se tratar de um estado mental dirigido a outro estado mental, que essas teorias são ditas "de ordem superior". A "ordem superior" nesse contexto, não tem a ver com nenhum aspecto valorativo. Essa expressão significa, simplesmente, que temos um estado mental de "segunda ordem" dirigido a um estado mental dito de "nível básico" ou de "primeira ordem" (cf. ROSENTHAL, 2008b, p. 835).

E a analogia da consciência com a percepção se mostraria no fato de que a percepção nos fornece conhecimentos a respeito de seus objetos, assim como a consciência (na sua noção mais sofisticada) nos torna cientes de nossos próprios estados mentais. Como esclarece Armstrong: "pela percepção sensorial nos tornamos cientes das ocorrências físicas que estão tendo lugar em nosso ambiente e em nosso corpo. Pelo sentido interno nos tornamos cientes das ocorrências que estão tendo lugar em nossa própria mente." (ARMSTRONG, 1968, p. 95). Nesta última passagem citada, Armstrong está se referindo àquela que, na sua concepção, é a forma mais importante de consciência, a consciência introspectiva.

$\mathrm{Na}$ teoria dele, fenômenos mentais a respeito de algo (como, por exemplo, a percepção de objetos externos) são uma forma de consciência (justamente a consciência perceptiva), mas não a forma mais elaborada. ${ }^{11}$ A forma mais desenvolvida da consciência (que viabilizaria uma interação mais complexa com o meio) é a consciência introspectiva, isto é, a percepção que um indivíduo tem dos seus próprios fenômenos mentais. Se a consciência de um fenômeno mental consiste em ele ser percebido, isto é, ser objeto de um fenômeno mental (perceptivo) de segunda ordem, isso faz da consciência de um fenômeno mental algo muito semelhante à percepção de um objeto ou de um estado de coisas no mundo extra psíquico, situação caracterizada pela dualidade entre a observação e o objeto observado. ${ }^{12}$

O objetivo do presente trabalho é oferecer uma avaliação da teoria de Armstrong a respeito da consciência e de sua concepção do inconsciente, de modo a elucidar tanto as suas vantagens quanto os seus próprios defeitos. Em primeiro lugar, será discutido em que sentido Armstrong defende uma perspectiva anti-

\footnotetext{
${ }^{10}$ A palavra "ciência", neste contexto, traduz a palavra "awareness", da língua inglesa, designando a característica de estar ciente de algo.

${ }^{11}$ A consciência perceptiva é uma forma de consciência diferente da consciência caracterizada na citação acima (cf. ARMSTRONG, 1968, p. 95), que é a consciência introspectiva. A consciência perceptiva é caracterizada por Armstrong como "consciência do que está ocorrendo no ambiente e no próprio corpo" (ARMSTRONG, 1997, p. 723). Assim sendo, como evidencia o exemplo do motorista de caminhão (exposto a seguir), é perfeitamente coerente que um episódio de consciência perceptiva seja inconsciente do ponto de vista da consciência introspectiva.

12 Para Armstrong, quando há consciência dos próprios estados mentais, o que ocorre é que "uma parte do cérebro examina uma outra parte do cérebro. Na percepção, o cérebro examina o ambiente. Na ciência da percepção, outro processo no cérebro examina esse exame." (ARMSTRONG, 1968, p. 94 - grifos acrescentados). Em outra passagem, ele acentua que "Percepção é um assunto causal" (ARMSTRONG, 1997, p. 725), o que implica a dualidade entre causa e efeito que, neste caso, subjaz à dualidade entre o objeto (que afeta) e o sujeito (que é afetado por ele).
} 
cartesiana, a saber: no sentido de que ele considera a consciência (de estados mentais) como um desenvolvimento ulterior, baseado em fenômenos mentais ${ }^{13}$ pré-existentes (fenômenos que existem previamente e independentemente da consciência - cf. ARMSTRONG, 1997, p. 721) (seção 2). Em seguida, serão discutidas as noções, propostas por Armstrong, de (1) consciência mínima (a presença de algum tipo de atividade mental) e de (2) consciência perceptiva (a percepção - baseada em interações causais - de objetos e estados de coisas externos) (seção 3), bem como o conceito de (3) consciência introspectiva (a percepção dos próprios estados, eventos e processos mentais) (seção 4).

A tese defendida aqui é que, apesar do valor explicativo de seus três conceitos de consciência, e apesar de oferecer um quadro teórico que favorece nossa compreensão do inconsciente, Armstrong tem uma visão insatisfatória a respeito dos fenômenos mentais inconscientes, pois essa visão não dá conta do real poder do inconsciente em nossa vida psíquica (seção 5).

\section{A PERSPECIIVA ANTI-CARIESIANA}

Antes de mais nada, é importante perceber que Armstrong argumenta em favor de uma concepção anti-cartesiana da mente, no sentido de uma concepção na qual a consciência não é o aspecto essencial do mental, inclusive porque, segundo ele, parece perfeitamente razoável admitir que mesmo uma pessoa que estivesse totalmente inconsciente ainda teria uma mente, no sentido de ainda ser capaz de instanciar pelo menos algumas propriedades mentais. Armstrong afirma claramente que: "Existe, porém, uma tese sobre a consciência que eu creio poder ser rejeitada com confiança: a doutrina de Descartes de que a consciência é a essência da mentalidade." (ARMSTRONG, 1997, p. 721). Ele entende essa doutrina como baseada na assunção de que podemos explicar a mente em termos da consciência, mas ele acha que "a verdade vai na direção contrária. Na verdade, no sentido mais interessante da palavra 'consciência', a consciência é o creme sobre o bolo da mentalidade, um desenvolvimento especial e sofisticado da mentalidade. Ela não é o bolo em si” (ARMSTRONG, 1997, p. 721).

Evidentemente, tal perspectiva se encaixa perfeitamente com a aceitação de fenômenos mentais inconscientes, pois, como enfatiza Armstrong, ao recusar a consciência como o fundamento da mente, nós somos "forçados a admitir a possibilidade lógica de nos encontrarmos em um estado mental, mas não estarmos cientes de que nos encontramos nesse estado. Isso quer dizer, temos de admitir a possibilidade lógica de estados inconscientes." (ARMSTRONG, 1968, p. 113). Ele fundamenta essa possibilidade lógica de fenômenos mentais inconscientes alegando que "se a ciência introspectiva [introspective awareness] e seus objetos são 'existências distintas', como argumentamos, então tem que ser possível para os objetos que eles existam quando a ciência não existe" (Ibid, p. 114).

13 Tais fenômenos mentais são entendidos por Armstrong como idênticos a estados neurofisiológicos do sistema nervoso central, cf. ARMSTRONG (1968, p. 89-90). 
Mas Armstrong não se limita a admitir a simples possibilidade lógica da existência de fenômenos mentais inconscientes, "pois existem suficientes casos empíricos que podem ser interpretados naturalmente como implicando a existência atual de estados mentais dos quais não estamos cientes” (Ibid., p. 114), casos empíricos como os que serão discutidos a seguir, ao longo do presente trabalho (vide o caso do historiador, ou o caso do motorista de caminhão, discutidos abaixo). É em virtude de tudo isso que ele não tem reservas em considerar sua própria visão da mente como similar, em suas linhas básicas, àquela defendida por Freud:

Em todos os momentos haverá estados e atividades de nossa mente dos quais nós não estamos introspectivamente cientes [aware]. Esses estados e atividades podem ser ditos estados e atividades mentais inconscientes em um bom sentido da palavra 'inconsciente' (ele é próximo do sentido freudiano, mas não há necessidade de sustentar que ele sempre envolve o mecanismo de repressão [repression]). (ARMSTRONG, 1997, p. 724).

Para compreender essa perspectiva a respeito da mente, devemos examinar as formas de existência mental independente de consciência, que são discutidas por Armstrong em relação aos três diferentes conceitos de consciência distinguidos por ele: (1) consciência mínima, (2) consciência perceptiva e (3) consciência introspectiva.

\section{CONSCIÊNCIA MÍNIMA E CONSCIÊNCIA PERCEPIIVA}

Se a consciência não é algo constitutivo da mente, mas apenas "um desenvolvimento especial e sofisticado da mentalidade" (ARMSTRONG, 1997, p. 721), é importante compreender como ela se desenvolve a partir do alicerce formado pelos fenômenos mentais. De acordo com Armstrong, estados (eventos e processos) $)^{14}$ mentais são aqueles que são aptos a provocar um comportamento de certo tipo (cf. ARMSTRONG, 1968, p. 82, p. 89) - sendo que ele entende que eles devem ser identificados com estados puramente físicos do sistema nervoso central (cf. Ibid., p. 89-90). No meu modo de entender, se consciência, de acordo com as três noções propostas por Armstrong, é algo de natureza mental, então tem que ser, na visão dele, algo capaz de provocar efeitos sobre o comportamento. Mas consciência, do modo como ele a entende, é algo que diz respeito a fenômenos mentais de natureza perceptiva: ele fala de "consciência" em termos de "reações comportamentais ao ambiente" (ARMSTRONG, 1997, p. 721), no sentido de que uma pessoa em um sono sem sonhos, ou sob anestesia total ainda possui alguma

\footnotetext{
${ }^{14}$ Armstrong enfatiza que seu uso do termo "estado" não é pensado de modo a excluir eventos e processos (cf. ARMSTRONG, 1968, p. 82). Ele entende que a noção de estado exprime a permanência de uma propriedade durante certo período, enquanto a noção de processo diz respeito a uma mudança que exige um certo tempo para ser completada (pois o estado existe inteiro durante o tempo em que uma propriedade permanece), e a noção de evento diz respeito ao surgimento ou desaparecimento de um estado (cf. Ibid., p. 130-131). Seguindo as caracterizações de Jaegwon Kim (1996, p. 06), podemos entender um estado como a instanciação continuada de uma propriedade, um evento como a mudança instantânea de uma propriedade para outra, e processos como sequências articuladas de estados e eventos.
} 
ciência (awareness) mínima do ambiente, ${ }^{15}$ "percepções do ambiente e do próprio corpo" (Ibid., p. 723), e em termos de "percepção do mental" (Ibid., p. 724). Se entendermos que "reações" ao ambiente supõem algum tipo de percepção, então o caráter perceptivo das três formas de consciência se torna claro, e já que a percepção é algum tipo de atividade mental, ou seja, algo que consiste em eventos e processos (e não em estados) mentais, então fica evidente o caráter dinâmico da consciência, nas três formas concebidas por Armstrong.

Se for assim, se torna compreensível porque Armstrong inicia suas considerações partindo do tipo de situação em que a consciência está (pelo menos aparentemente) ausente, como o caso de um sono sem sonhos: ele quer contrastar a situação em que existem eventos e processos mentais (como os processos perceptivos que constituem a consciência) com a situação em que existem apenas estados mentais (que constituem uma mentalidade inerte). Na ausência de qualquer atividade mental (como, p. ex., processos perceptivos) uma pessoa ainda possui mente no sentido de se encontrar em um imenso número de estados mentais. Armstrong dá o exemplo de um historiador especializado no período medieval: mesmo que ele estivesse em um sono sem sonhos, se nenhum evento ou processo mental ocorresse durante um certo período (ou seja, se não ocorresse nenhuma modificação psicológica), nós não negaríamos que ele possui um grande conjunto de conhecimentos e crenças acerca da idade média. Do mesmo modo, a uma pessoa totalmente inconsciente podem ser atribuídas memórias, habilidades, gostos, atitudes, emoções, desejos, propósitos etc. (que segundo uma concepção materialista da mente podem ser pensados como codificados fisicamente na estrutura do cérebro - cf. ARMSTRONG, 1997, p. 722; ARMSTRONG, 1968, p. 8687). Por outro lado, existe uma série de atribuições mentais que nós não faríamos a uma pessoa totalmente inconsciente, como ter sensações, percepções ou explosões de desejo. Essa pessoa não pode pensar, contemplar ou se engajar em nenhum tipo de deliberação. O motivo pelo qual nós não faríamos essas atribuições é que sensações, percepções, explosões de desejo, pensamentos, contemplações e deliberações são atividades mentais, enquanto conhecimentos e crenças não são. A esse respeito o autor escreve:

A distinção parece ser, aproximadamente em todo caso, a distinção entre eventos e ocorrências por um lado, e estados, por outro. Quando um estado mental produz efeitos mentais, o vir-a-ser [comings-to-be] de tais efeitos são eventos mentais: e assim atividade mental está envolvida. (ARMSTRONG, 1997, p. 722).

\footnotetext{
15 Ao considerar que há uma ciência mínima, devido à presença de reações comportamentais, Armstrong parece estar considerando a "ciência" [awareness] em questão como algo semelhante àquilo que Gennaro chama de "ciência comportamental" [behavioral awareness], isto é: possuir estados internos, dotados de conteúdo proposicional, que são capazes de dirigir o comportamento da criatura em questão (cf. GENNARO, 1996, p. 06). Na visão dele, a ciência comportamental não implica ciência consciente, o que o leva a dizer, numa clara referência a Armstrong, que "o motorista de caminhão em longas distâncias está 'comportamentalmente ciente' das curvas na estrada” (Ibid., p. 06).
} 
Armstrong propõe que, em situações onde alguma espécie de atividade mental ${ }^{16}$ está ocorrendo seja usado o conceito de consciência mínima (minimal consciousness) - pensemos, por exemplo, no caso de pessoas que despertam sabendo a solução para um problema matemático, a qual eles desconheciam antes de ir dormir: parece necessário admitir que ocorreu atividade mental durante o sono (cf. ARMSTRONG, 1997, p. 722).

Neste ponto, Armstrong parece estar traçando uma diferença entre (a) a questão de um sujeito - ou um organismo - estar, ou não, desperto e (b) a questão de ele exemplificar, ou não, eventos e processos mentais. Para compreender melhor o conceito de consciência mínima proposto por Armstrong, é interessante considerar, mesmo que rapidamente, uma distinção proposta por outro importante filósofo da mente, David Rosenthal, ${ }^{17}$ a saber, a distinção entre (a) consciência de criatura e (b) consciência de estado. De acordo com Rosenthal:

Dois assuntos são frequentemente confundidos nas discussões sobre a consciência. Uma questão é: o que é para um estado mental ser consciente. Supondo que nem todos os estados mentais são conscientes, nós queremos saber como os estados conscientes se diferenciam daqueles que não são. E ainda que todos os estados mentais fossem conscientes, nós ainda perguntaríamos em que consiste a sua consciência. Denominamos essa a questão da consciência de estado. Esse será meu principal tema no texto que segue. Mas nós não descrevemos apenas estados mentais como sendo conscientes ou não; nós também atribuímos consciência a criaturas. Assim, existe uma segunda questão, a questão sobre o que é para uma pessoa ou outra criatura ser consciente, ou seja, como criaturas conscientes se diferenciam daquelas que não são conscientes. Denominamos esta a questão da consciência de criatura. (ROSENTHAL, 1997, p. 729; ROSENTHAL, 2017, p. $144-$ grifos acrescentados).

Rosenthal entende que a questão da consciência de criatura, ou seja, a questão a respeito do que é para uma criatura, ou um organismo, estar consciente em dadas circunstâncias, não é um grande desafio para a reflexão filosófica, pois, segundo ele, nós dispomos de uma noção intuitiva do que é, em termos gerais, para um organismo estar consciente, a saber: tal organismo tem que estar desperto e sensível a seu ambiente circundante (cf. ROSENTHAL, 1997, p. 730; ROSENTHAL, 2017, p. 144). ${ }^{18}$ Por isso ele elege a consciência de estado como o objeto de sua teoria da consciência.

E a consciência de estado, isto é, a consciência como uma característica de estados (eventos e processos) mentais, é pensada por Rosenthal em termos de

\footnotetext{
${ }^{16}$ Entendo que aquilo que Armstrong designa como "atividades mentais" corresponde claramente aos eventos e processos mentais na categorização de Kim (1996).

17 Para uma discussão das três distinções referentes à consciência propostas por Rosenthal, cf. PRATA, 2017, p. 433-37.

${ }^{18} \mathrm{O}$ influente filósofo australiano David Chalmers parece convergir com Rosenthal nesse ponto, quando ele afirma que a questão do que é para um organismo estar desperto é um tema para as ciências empíricas. Nas palavras de Chalmers: "Para uma explanação do sono e da vigília, será suficiente uma adequada explanação neurofisiológica dos processos responsáveis pelo comportamento contrastante do organismo nesses estados" (1995, p. 201).
} 
nossa consciência deles. De acordo com ele: "estados conscientes são simplesmente estados mentais dos quais estamos conscientes de nos encontrar" (ROSENTHAL, 1986, p. 335), de modo que, como será detalhado posteriormente, a consciência como característica de um estado mental é pensada em termos da relação entre esse estado e o sujeito que o vivencia, no sentido de que esse sujeito "está transitivamente consciente daquele estado" (ROSENTHAL, 1997, p. 739; ROSENTHAL, 2017, p. 162). ${ }^{19}$

É interessante notar que, na teoria de Armstrong, haveria consciência mínima quando a consciência de criatura está ausente (ou seja, quando o organismo está desacordado) mas, mesmo assim, há algum tipo de atividade mental, no sentido de que, para além de simples estados (que não implicam nenhuma atividade), pelo menos algum evento ou processo mental tem lugar no psiquismo dessa criatura, o que, na visão materialista de Armstrong, significa apenas que certos processos cerebrais estão ocorrendo. E é importante notar também que, quando há consciência mínima, também a consciência de estado está ausente, pois as atividades mentais que constituem a consciência mínima são claramente, na descrição de Armstrong, atividades inconscientes. Portanto, a noção de consciência mínima proposta por ele se restringe a designar atividades mentais (idênticas a certos processos eletroquímicos no cérebro), que podem ter consequências no comportamento do organismo, mas permanecem desprovidas de consciência (no sentido de que o sujeito não tem consciência delas).

Nesse sentido, a noção de consciência mínima estabelece um contexto no qual a noção de inconsciente está envolvida, tanto no que diz respeito a criaturas, quanto no que diz respeito a seus estados (eventos e processos) mentais. Em outras palavras, a noção de consciência mínima implica, na verdade, duas noções de inconsciente (evidenciadas pela primeira distinção de Rosenthal).

Portanto, fica claro que essas situações, nas quais ocorre aquilo que Armstrong chama de "consciência mínima", certamente não são nosso referencial quando nos referimos ao fenômeno da consciência, pois a consciência mínima ocorre em circunstâncias que, cotidianamente, são chamadas de "inconsciência". Quando falamos de consciência, levamos em consideração outros fatores, e ele destaca que entre esses fatores, está a capacidade de percepção por parte do ser em questão. Consciente, em um sentido importante da palavra, é o ser capaz de perceber o que se passa ao seu redor e no seu próprio corpo. ${ }^{20}$ Se um indivíduo humano, p. ex., está dormindo, mas alguma atividade mental está em curso, então ele tem o que Armstrong chama de consciência mínima, mas ainda lhe falta algo para que se atribua a ele consciência no sentido usual da palavra. A partir do momento em que o indivíduo seja novamente capaz de percepção, algo importante

\footnotetext{
${ }^{19} \mathrm{O}$ conceito de consciência transitiva será explicitado a seguir.

20 "Entre as atividades mentais, porém, parece que nós fazemos uma ligação especial entre consciência e percepção. Na percepção, existe consciência do que está ocorrendo atualmente no ambiente de alguém e em seu próprio corpo (claro que a consciência pode envolver ilusão). Existe um sentido importante no qual se uma pessoa não está percebendo, então não está consciente, mas se percebe, então está consciente" (ARMSTRONG, 1997, p. 723). Esta passagem deixa claro o caráter intencional da consciência perceptiva, ou seja, o seu caráter de ser acerca ou a respeito de algo.
} 
foi acrescentado, aquilo que o autor chama de consciência perceptiva (perceptual consciousness).

É interessante notar que a distinção entre (a) consciência de criatura e (b) consciência de estado, proposta por Rosenthal, também é relevante para a compreensão da consciência perceptiva, tal como concebida por Armstrong, pois, por um lado, a consciência perceptiva costuma acontecer quando a consciência de criatura está presente (embora o exemplo do motorista de caminhão, discutido abaixo, poderia levar alguém a argumentar que a consciência perceptiva pode acontecer quando a consciência de criatura está ausente) e, por outro lado, a consciência perceptiva ocorre quando estão presentes certos estados mentais, justamente as percepçôes, do próprio corpo ou do ambiente circundante. ${ }^{21}$ Nesse sentido, essa distinção de Rosenthal ajuda a delinear certos aspectos presentes na noção de consciência perceptiva de Armstrong.

Mas além disso, há uma segunda distinção proposta por Rosenthal, a distinção entre (a') consciência intransitiva e (b') consciência transitiva, e ela também é pertinente para elucidar o conceito de consciência perceptiva, pois a percepção é um exemplar de consciência transitiva. De acordo com Rosenthal:

Colocando a consciência de criatura de lado, podemos distinguir duas maneiras como usamos a palavra 'consciente'. Uma é quando falamos de nosso estar consciente de alguma coisa. Por causa do objeto direto, devo chamar esse uso de transitivo. Mas nós também aplicamos o termo 'consciente' a estados mentais, para dizer que eles são estados conscientes. Isso é o que eu rotulei como consciência de estado. A falta de um objeto direto sugere chamar esse uso de intransitivo. Esse uso intransitivo tem lugar somente quando falamos de estados mentais, ao passo que nós falamos de estar consciente, transitivamente, tanto de coisas físicas quanto mentais. Nós podemos estar transitivamente conscientes de uma pedra, de uma sinfonia, ou de um estado mental. (ROSENTHAL, 1997, p. 737; ROSENTHAL, 2017, p. 158-159-grifos acrescentados).

Nesta passagem, Rosenthal está tratando de algo que já foi mencionado anteriormente, na introdução do presente artigo (cf. também GENNARO, 1996, p. 03), a saber: ele está tratando da distinção entre (a') consciência enquanto uma propriedade expressa por um predicado monádico (p. ex. “... é consciente”, que é um predicado intransitivo) onde o lugar vazio pode ser preenchido com a designação de uma criatura ou de um estado mental e (b') consciência enquanto uma propriedade expressa por um predicado diádico (p. ex. “... é consciente de ..." que é um predicado transitivo) onde o primeiro lugar vazio tem que ser substituído pela designação de uma criatura $^{22}$ e o segundo lugar vazio pode ser preenchido com a designação de um fenômeno físico ou de um fenômenos

\footnotetext{
${ }^{21}$ Sendo uma percepção um estado mental, coloca-se a pergunta sobre se esse estado é, em dado momento, consciente, ou não.

${ }^{22}$ Rosenthal afirma claramente que "Ser transitivamente consciente de algo é uma relação na qual uma pessoa ou outra criatura está com esse algo. Assim, apenas criaturas podem estar transitivamente conscientes de coisas" (ROSENTHAL, 1997, p. 738; ROSENTHAL, 2017, p. 160 grifo acrescentado). A esse respeito, cf. Kriegel (2009, p. 27).
} 
mental. ${ }^{23}$ O ponto a ser destacado é que a consciência perceptiva de Armstrong é um tipo específico daquilo que Rosenthal denomina "consciência transitiva". Como esclarece Rosenthal:

Podemos chamar esse fenômeno de consciência transitiva. Alguém está consciente de algo quando vê ou escuta esse algo, ou o sente e percebe de algum outro modo. Ter um pensamento sobre algo algumas vezes também é suficiente para se ter consciência desse algo, mas não sempre. (ROSENTHAL, 2008a, p. 239). ${ }^{24}$

Entretanto, a distinção entre (a') consciência intransitiva e (b') consciência transitiva envolve uma sutileza à qual precisamos prestar muita atenção, pois essa sutileza é decisiva para que possamos compreender o próximo conceito de consciência proposto por Armstrong. O ponto é: no que uma percepção é percepção de algo ela é uma forma de consciência transitiva, a saber, uma consciência perceptiva de um objeto. Nesse sentido, a percepção desfruta da característica que o debate filosófico contemporâneo, desde Brentano, chama de Intencionalidade, ${ }^{25}$ característica esta que mesmo as percepções que não são objeto de introspecção (ou seja, as percepções inconscientes) possuem. ${ }^{26}$ Por outro lado, se a percepção de um objeto externo é consciente - e a tradição cartesiana argumenta que ela é necessariamente consciente - então, se trata de consciência intransitiva, pois apesar do fato de a percepção ser transitiva, ela pode ser descrita de uma perspectiva na qual podemos atribuir a ela (a percepção) uma propriedade expressa por um predicado monádico.

Se, por exemplo, digo que "minha percepção do pôr do sol é consciente", (no sentido de que eu estou consciente da percepção - cf. ROSENTHAL, 1986, p. 335; ROSENTHAL, 1997, p. 739; ROSENTHAL, 2017, p. 161) a consciência, nessa frase entre aspas, está sendo apresentada como uma propriedade não relacional dessa percepção, e essa propriedade não relacional é o que Rosenthal chama de consciência intransitiva. Para perceber isso com mais clareza, basta trocar a descrição "percepção do pôr do sol" (descrição que expressa uma consciência transitiva) pela abreviação "P", pois se digo que "P é consciente", embora P envolva

\footnotetext{
${ }^{23}$ Como coloca Rosenthal: "Nós podemos estar transitivamente conscientes de uma pedra, de uma sinfonia, ou de um estado mental" (ROSENTHAL, 1997, p. 737; ROSENTHAL, 2017, p. 159).

${ }^{24}$ Não sempre porque apenas pensamentos assertóricos são capazes de tornar consciente o estado mental a respeito do qual eles são, e nem todo pensamento é assertórico.

${ }^{25} \mathrm{Na}$ mais famosa passagem de sua Psicologia do ponto de vista empírico, publicada originalmente em 1874, Brentano escreveu: "Todo fenômeno psíquico é caracterizado por aquilo que os escolásticos da idade média denominaram o 'existir em' [Inexistenz] intencional [...], o que nós denominaríamos, embora não com expressões totalmente precisas, a relação a um conteúdo, a direção a um objeto (com o que não se deve entender aqui uma realidade), ou a objetividade imanente. Todo fenômeno psíquico contém em si algo como objeto, embora não todos do mesmo modo. Na representação algo é representado, no juízo algo é reconhecido ou recusado, no amor amado, no ódio odiado, no desejo desejado, etc." (BRENTANO, 1924, p. 124-125; BRENTANO, 1995, p. 88). Se percebo o por do sol, essa minha percepção efetiva uma consciência de, ou seja, uma consciência direcionada a um certo estado de coisas.

${ }^{26}$ É interessante notar que Armstrong reconhece a tese de Brentano de que a Intencionalidade é a marca do mental, por mais que ele não aceite que isso signifique uma diferença entre o mental e o físico. De acordo com ele: "É claro que nenhum fisicalista pode aceitar a irredutibilidade da intencionalidade, embora ele possa aceitar a visão de Brentano de que a intencionalidade é a marca do mental" (ARMSTRONG, 1968, p. 41).
} 
uma relação com o seu objeto (em nosso exemplo, uma relação intencional com o sol), o que está sendo expresso é uma propriedade intransitiva, expressa por um predicado monádico. ${ }^{27}$

Mas por que essa sutileza é importante? Porque, como vimos, Armstrong rejeita a visão cartesiana e defende que estados mentais, mesmo os que são consciência transitiva de um objeto, podem existir independentemente da consciência. E isso significa que esses estados mentais, no que são inconscientes, existem desprovidos de consciência intransitiva, ou seja, eles existem desprovidos da propriedade expressa pelo predicado monádico "... é consciente".

A esse respeito, é importante perceber que, apesar de a expressão "consciência inconsciente" parecer, à primeira vista, contraditória, ela pode ser empregada de uma maneira que é perfeitamente razoável (se ela for construída com dois sentidos distintos de "consciência"). Uma maneira de dissipar a impressão de contradição é substituir o termo "consciência" (consciousness) pelo termo "ciência" (awareness) - formando, então a expressão "ciência inconsciente" - pois, como esclarece Gennaro:

É claro que 'ciente' (aware) e 'consciente' (conscious) não são meramente sinônimos [...]. Não é contraditório falar de ser 'inconscientemente ciente' de algo. De modo similar, a expressão 'conscientemente ciente' não é redundante. Ciência não necessariamente carrega conotações de consciência. (GENNARO, 1996, p. 05).

Para perceber isso, basta pensar que eu, por exemplo, estou sempre ciente de que nasci em uma cidade localizada ao sul do equador, embora muito raramente eu pense sobre isso de forma consciente. Sendo assim, é perfeitamente razoável dizer que estou, durante a maior parte do tempo, inconscientemente ciente desse fato.

Mas voltando para a questão da consciência como propriedade de estados mentais, é importante perceber que o que garante que estados mentais, eventualmente, desfrutem daquilo que Rosenthal chama de "consciência intransitiva", é uma terceira forma de consciência, que não se confunde com (1) a consciência mínima nem com (2) a consciência perceptiva de objetos externos (embora, na verdade, seja uma forma específica de consciência perceptiva, como veremos). A questão é que, para Armstrong, mesmo se há (1) atividade mental ocorrendo, e se essa atividade mental inclui também (2) percepção genuína (e não

\footnotetext{
${ }^{27}$ Mas é importante ter em vista que essa propriedade intransitiva, como já foi aludido acima, é pensada por Rosenthal como decorrente de uma relação: a relação com o sujeito. De acordo com ele: "a consciência intransitiva de um estado mental é simplesmente uma certa maneira do indivíduo estar transitivamente consciente daquele estado" (ROSENTHAL, 1997, p. 739; ROSENTHAL, 2017, p. 162). Embora não seja um defensor da perspectiva de ordem superior, o filósofo Uriah Kriegel argumenta a favor da plausibilidade da tese de que o caráter subjetivo de um estado mental consciente (caráter em virtude do qual esse estado se manifesta ao sujeito) implica uma consciência do estado mental, pois "seria, de fato, bastante estranho manter que uma experiência é para o sujeito ainda que o sujeito não tenha nenhuma ciência dela. Uma vez que essa ciência [awareness] é ciência-de, ela envolve uma relação transitiva [of-ness relation] com a experiência" (KRIEGEL, 2009, p. 104).
} 
o tipo de experiência que ocorre em um sonho ou em uma alucinação), ainda há algo importante que pode estar ausente: aquilo que Armstrong chama de (3) consciência introspectiva.

\section{CONSCIÊNCIA INIROSPECTIVA}

Se a consciência perceptiva foi caracterizada acima como uma consciência dos acontecimentos e objetos do ambiente (cf. ARMSTRONG, 1968, p. 95; ARMSTRONG, 1997, p. 723), a consciência introspectiva, evidentemente, pode ser caracterizada como uma capacidade através da qual "nos tornamos cientes das ocorrências que estão tendo lugar em nossa própria mente" (ARMSTRONG, 1968, p. 95). Ao caracterizar a consciência introspectiva como uma "percepção do mental" ou um "sentido interno" (ARMSTRONG, 1997, p. 724), Armstrong está ciente de estar levando adiante uma antiga tradição filosófica, que ele identifica em autores como Locke e Kant (cf. ARMSTRONG, 1968, p. 95; ARMSTRONG, 1997, p. 724), tradição que, aliás, é muito mais antiga do que esses autores, remontando aos primórdios da filosofia ocidental. Para explicar do que se trata, o autor apresenta uma situação - bastante conhecida na literatura em filosofia da mente e já vivenciada por diversas pessoas ${ }^{28}$ em situações peculiares:

Depois de dirigir por longos períodos de tempo, particularmente à noite, é possível 'chegar' [to 'come to] e se dar conta de que por algum tempo a pessoa estava dirigindo sem estar ciente [aware] do que estava fazendo. Se dar conta disso é uma experiência alarmante. É natural descrever o que aconteceu antes da pessoa se dar conta dizendo que durante aquele período ela carecia de consciência. (ARMSTRONG, 1997, p. 723).

Nesse exemplo, parece bastante claro que, nos dois sentidos propostos por Armstrong que discutimos até agora, consciência tinha lugar, pois havia (1) atividade mental e também (2) percepção, como prova a sequência de tarefas bastante complexas que o indivíduo executou naquele período, afinal ele dirigiu o veículo ao longo da estrada (talvez por vários quilômetros durante alguns minutos). Se ele tivesse parado de perceber o ambiente ao seu redor certamente um acidente teria ocorrido. Armstrong afirma que é necessário admitir, no mínimo, que nessa situação os olhos e o cérebro têm que ter sido estimulados exatamente da mesma maneira que em casos comuns de percepção. "Por que então negar que percepção ocorreu?" (ARMSTRONG, 1997, p. 723). ${ }^{29}$ Mas mesmo se admitirmos que havia consciência mínima e consciência perceptiva, parece claro que algo mais

\footnotetext{
${ }^{28}$ Embora eu mesmo nunca tenha vivenciado algo assim, conheço diversas pessoas que relatam experiências semelhantes a essa mencionada por Armstrong.

${ }^{29}$ É possível que muitos (provavelmente simpatizantes da visão cartesiana) negassem que se trata de percepção propriamente dita, na medida em que nenhuma vivência (experience) teve lugar, isto é, na medida em que não estava presente nenhum aspecto fenomenológico. Mas o ponto de Armstrong parecer ser o de que algo ocorreu no sujeito que desempenhou a função que a percepção desempenharia em uma situação normal, de modo que isso que ocorreu nesse caso atípico mereceria ser chamado de "percepção".
} 
estava ausente, aquilo que o autor considera o sentido mais interessante da palavra "consciência".

O caso do motorista de caminhão pode parecer extraordinário (dirigir o veículo por algum tempo sem ter tido ideia do que estava fazendo), mas, para Armstrong, tal caso diz respeito a um nível relativamente simples, em termos evolucionários, de atividade mental: ação voltada para um objetivo e guiada por percepção. Ele especula que talvez muitos animais, que têm um sistema nervoso menos desenvolvido do que o nosso, vivam continuamente (ou pelo menos a maior parte do tempo) no estado em que o motorista ficou durante alguns minutos. Talvez a terceira forma de consciência que estava ausente seja um desenvolvimento evolucionário tardio. Armstrong caracteriza essa forma de consciência como se segue:

O que faltava ao motorista de caminhão de longa distância? Eu penso que é uma forma adicional de percepção ou, um pouco mais cautelosamente, é algo que se assemelha à percepção. Mas diferente da percepção sensorial, ela não é dirigida ao nosso ambiente e/ou ao nosso estado corporal em curso. É percepção do mental. Tal percepção 'interna' é tradicionalmente chamada de introspecção, ou ciência [awareness] introspectiva. Nós podemos, portanto, chamar esse terceiro tipo de consciência de consciência 'introspectiva'. (ARMSTRONG, 1997, p. 724).

A consciência introspectiva, claramente, implica consciência mínima (a presença de algum tipo de atividade mental). Mas, de acordo com Armstrong, se o conceito de consciência perceptiva for restringido à percepção do exterior e do próprio corpo através dos sentidos, então a consciência introspectiva não implica consciência perceptiva (o que, no meu entendimento, significa que a consciência introspectiva não tem necessariamente que ser a respeito de percepções - pode ser também a respeito de memórias, emoções, desejos, etc.). A consciência introspectiva é, na concepção dele, uma ciência (à maneira da percepção) dos estados e atividades em curso na própria mente de um indivíduo, sendo que tais atividades podem incluir a percepção sensorial (do mundo externo e do próprio corpo), mas podem também não incluir. Podemos representar a consciência introspectiva de uma percepção (que é um tipo entre diferentes outros tipos de fenômenos mentais) através da seguinte figura:

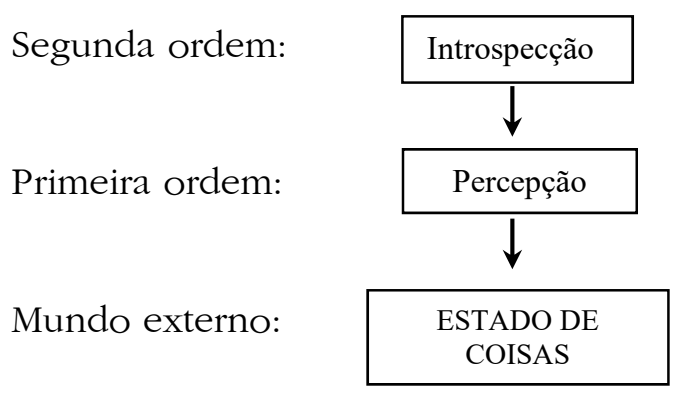


Interessante é que a consciência introspectiva, na medida em que é uma atividade mental, pode se tornar ela própria objeto de uma introspecção ulterior. É importante notar que Armstrong distingue entre uma introspecção espontânea, responsável pela consciência de todo e qualquer estado mental efetivamente consciente, e uma introspecção deliberada, que é justamente, essa introspecção da introspecção. Nesse sentido, é imprescindível perceber que a consciência introspectiva, tal como foi discutida acima, não é, em primeira linha, o esforço consciente de examinar o que se passa na própria mente, mas sim uma percepção interna, em certo sentido, espontânea, não planejada, que efetiva a consciência de um estado mental. Armstrong (1997, p. 725) denomina essa introspecção de "consciência introspectiva por reflexo" [ "reflex" introspective consciousness]. Já o esforço consciente de escrutinar os próprios fenômenos mentais é denominado por ele de "introspecção propriamente dita" [ "introspection proper"], algo que consistiria em uma percepção de terceira ordem que se volta para a percepção de segunda ordem que torna um dado fenômeno mental consciente. Trata-se de uma percepção de terceira ordem porque, assim como na introspecção por reflexo há "um outro estado mental, dirigido aos estados internos originais" (ARMSTRONG, 1968, p. 94), na introspecção propriamente dita tem que haver um outro estado mental que esteja dirigido ao segundo estado. ${ }^{30} \mathrm{~A}$ diferença entre essas duas formas de introspecção pode ser representada através da seguinte figura:
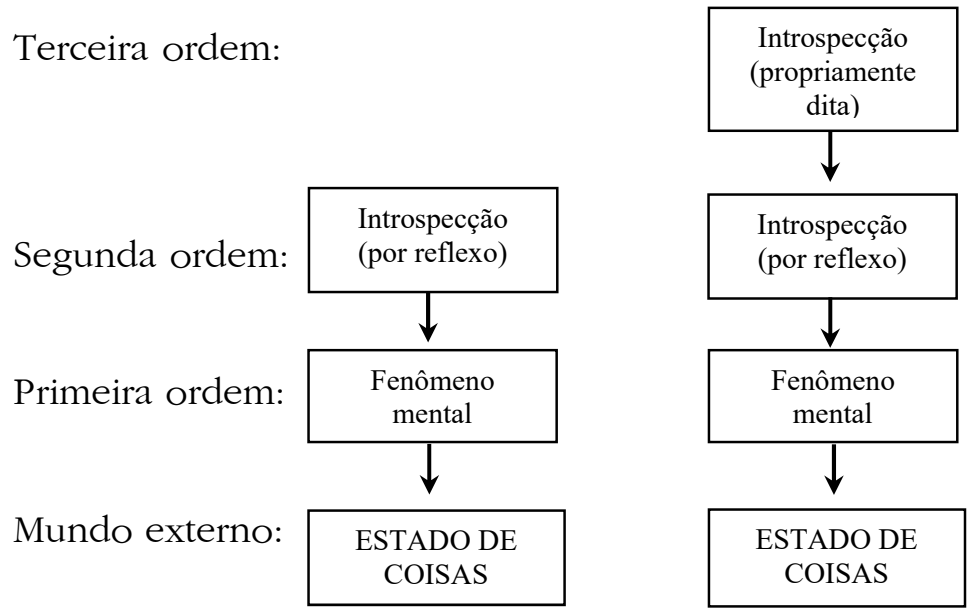

A esse respeito, penso que a terminologia de Armstrong é um pouco confusa, pois o termo "introspecção" sugere um esforço deliberado de autoexame (como o próprio Armstrong parece sugerir ao falar de uma "introspecção propriamente dita"), de maneira que o uso desse termo para designar a consciência, por assim dizer, espontânea de certos estados mentais, pode induzir a erro. Naquilo que Armstrong chama de "consciência introspectiva por reflexo", o que temos é o monitoramento de um estado mental por outro estado mental do mesmo indivíduo, e ele escolhe designar essa relação entre dois estados mentais

${ }^{30}$ Para uma discussão do conceito de introspecção, e dos diferentes níveis de estados mentais envolvidos, cf. Rosenthal (1986, p. 337). 
com a palavra "introspecção". Mas eu entendo que seria mais adequado respeitar o sentido específico dessa palavra, ${ }^{31}$ e reservá-la para aquilo que Armstrong chama de "introspecção propriamente dita", pois quando um estado mental está consciente (isto é, exemplifica a característica intransitiva de ser consciente) de modo espontâneo ("por reflexo", nos termos de Armstrong), a atenção do indivíduo está voltada para aquilo que é o tema desse estado mental. Neste ponto, a teoria de Armstrong pode ser iluminada através de uma terceira distinção conceitual operada por Rosenthal, a saber, a distinção entre consciência não introspectiva, por um lado, e consciência introspectiva, por outro. De acordo com Rosenthal:

Quando prestamos atenção deliberadamente ao estado mental no qual nos encontramos, estamos introspectivamente conscientes desse estado. Isso é diferente do modo como estados mentais são conscientes quando não estamos deliberadamente focando nossa atenção sobre eles. Introspecção é consciência atenta e deliberada de nossos estados mentais. É algo relativamente raro, e é algo mais elaborado do que a maneira na qual estados mentais são ordinariamente conscientes. (ROSENTHAL, 1997, p. 730; ROSENTHAL, 2017, p. 145 - grifo acrescentado).

As peculiaridades da introspecção se obscurecem quando se chama "introspectiva" essa consciência mais simples dos próprios estados mentais. Mas provavelmente Armstrong escolheu esse termo (que me parece pouco adequado) porque ele sugere um exame, ou um monitoramento da própria mente do sujeito que se encontra em estados mentais conscientes, ou seja, uma relação do sujeito com os seus próprios estados mentais. ${ }^{32}$

O caso é que, assim como a percepção sensorial não é uma atenção completa a todos os estados e processos em curso no ambiente e no próprio corpo, aquilo que Armstrong chama de consciência introspectiva não abrange a totalidade dos estados e processos em curso na mente de um indivíduo. Nas palavras dele:

Em todos os momentos haverá estados e atividades de nossa mente dos quais nós não estamos introspectivamente cientes [aware]. Esses estados e atividades podem ser ditos estados e atividades mentais inconscientes em um bom sentido da palavra 'inconsciente' (ele é próximo do sentido freudiano, mas não há necessidade de sustentar que ele sempre envolve o mecanismo de repressão [repression]). Tais estados e atividades mentais inconscientes podem naturalmente envolver consciência mínima e/ou consciência perceptiva, na verdade as atividades envolvem consciência mínima por definição. (ARMSTRONG, 1997, p. 724).

\footnotetext{
31 A diferença entre a consciência introspectiva e a simples consciência de estados mentais é elucidada por Gilbert Ryle nos seguintes termos: "Introspecção é uma operação atenta e que é realizada apenas ocasionalmente, enquanto que a consciência é suposta como um elemento constante de todos os processos mentais, e cujas revelações não exigem que sejam recebidas em atos especiais de atenção. Além disso, nós realizamos introspecção com a intenção de encontrar respostas para problemas específicos, enquanto que estamos conscientes quer desejemos ou não; todo mundo está constantemente consciente, enquanto desperto, mas somente aqueles que estão, de tempos em tempos, interessados no que ocorre em suas mentes realizam introspecção" (RYLE, 1970, p. 157).

32 Para conhecer os argumentos de Armstrong a favor de seu próprio uso do termo "introspecção", cf. Armstrong (1968, p. 95).
} 
E exatamente como a percepção externa não abrange tudo o que ocorre no ambiente, ela também é, além disso, potencialmente falha, pois pode não corresponder com exatidão à realidade. Do mesmo modo, também a consciência introspectiva pode falhar em corresponder com exatidão à realidade mental, o que leva Armstrong a rejeitar a tese cartesiana da indubitabilidade da consciência. ${ }^{33}$ É interessante notar que, ao considerar a introspecção potencialmente falha, como é a percepção externa, o autor, sugere a presença da dicotomia entre conhecimento e objeto dentro da própria mente. Da mesma maneira, quando considera uma concepção causal da introspecção a concepção mais plausível para um filósofo naturalista (cf. ARMSTRONG, 1997, p. 725), isto é, quando supõe que fenômenos mentais exercem poder casual sobre a introspecção (assim como fazem objetos externos sobre a percepção), Armstrong trata os fenômenos mentais como algo essencialmente separado da consciência introspectiva que se pode ter deles, o que parece fazer da introspecção uma relação cognitiva, uma forma de conhecimento.

Armstrong entende que a função biológica da consciência introspectiva é tornar nossa atividade mental mais sofisticada, de modo que essa atividade possa propiciar ações mais complexas. Uma vez que dispomos de uma capacidade perceptiva interna, que nos torna cientes [aware] dos estados e atividades mentais que estão em curso em nossa mente, se torna muito mais fácil integrar esses estados e atividades, ou seja: "colocá-los para trabalhar juntos de maneiras complexas e sofisticadas que são necessárias para se alcançar fins complexos e sofisticados" (ARMSTRONG, 1997, p. 726). Se a função biológica dos processos mentais é mediar os estímulos ambientais e a resposta do organismo, de modo a tornar esta resposta mais sofisticada e eficiente, a função biológica da introspecção é informar o agente daquilo que se passa em seu psiquismo, permitindo que ele trabalhe de modo mais eficaz os estímulos externos (e, eventualmente internos ao próprio organismo) e suas próprias reações a eles (cf. ARMSTRONG, 1968, p. 163).

Como exemplo do primeiro caso, podemos pensar em alguém confrontado com uma situação problema (como um cirurgião diante de uma súbita complicação em uma cirurgia, ou um investidor em dúvida sobre vender um ativo). Nessas circunstâncias, para Armstrong, "várias respostas possíveis podem ser tentadas 'na imaginação' para ver qual resposta vai satisfazer melhor os propósitos do agente. Como um resultado causal, a resposta pode ser muito mais eficiente" (ARMSTRONG, 1968, p. 163). Como exemplo do segundo caso (relativo a estímulos internos), Armstrong cita a situação em que alguém tem que lidar com a própria agressividade. De acordo com ele: "conhecimento da presença, dentro de nós, de potenciais causas de comportamento, é de um valor óbvio na condução da vida” (Ibid., p. 99).

\footnotetext{
33 A referência a Descartes sugere que Armstrong tem em vista nesta passagem aquilo que ele chama "introspecção propriamente dita" (1997, p. 725), que me parece corresponder ao que Rosenthal chama de "consciência introspectiva". Penso que essas considerações de Armstrong poderiam ser entendidas como uma refutação da incorrigibilidade afirmada por Descartes, mas não da indubitabilidade, pois, para o filósofo francês, o que é indubitável é o fato do "eu penso" e não os conteúdos do pensamento (que parecem ser o que Armstrong tem em mente com essas considerações).
} 


\section{CONSIDERAÇÕES FINAIS}

A discussão empreendida no presente trabalho, no meu modo de entender, mostra que a teoria de Armstrong sobre a consciência se revela interessante e fecunda para se pensar a respeito desse complexo conjunto de fenômenos, uma vez que as distinções propostas por ele (entre consciência (a) mínima, (b) perceptiva e (c) introspectiva) parecem tornar discerníveis aspectos importantes da consciência, e a partir do momento em que somos capazes de enxergar essas diferenças, nosso entendimento da consciência se amplia. Por mais que (i) desconsidere uma distinção importante acerca da consciência, como é a distinção entre consciência de criatura e consciência de estado, e por mais que (ii) não trace, com suficiente clareza, uma distinção bastante elucidativa, que é aquela entre consciência não introspectiva e consciência introspectiva (o que revela duas limitações importantes); a conceituação proposta por Armstrong se mostra bastante proveitosa para nossa compreensão da temática da consciência, uma vez que ela nos ajuda a discernir entre aspectos muito relevantes, como o são (a) as atividades mentais que, de algum modo, nos conectam com o mundo, (b) as conexões causais que nos tornam perceptivamente cientes do nosso ambiente imediato, e (c) nossa conexão com nossos próprios fenômenos mentais, que efetivam nossas relações psicológicas com o mundo (e com nós mesmos). Entendo que, apesar de suas limitações, os conceitos de consciência elaborados por Armstrong têm considerável valor para a reflexão teórica acerca dos diversos fenômenos que designamos com a palavra "consciência".

Além disso, uma teoria como essa representa um grande avanço em relação à tradição cartesiana, que entende a consciência como essencial aos fenômenos mentais, tradição que continuou influente no século XX através de autores como Brentano $^{34}$ e Sartre, ${ }^{35}$ e que continua a reverberar na atual filosofia da mente. ${ }^{36} \mathrm{~A}$ visão cartesiana da consciência se mostra muito inadequada para explicar os abundantes indícios de que há toda uma vasta vida mental inconsciente (cf. ROSENTHAL, 1986, p. 329, p. 334; ROSENTHAL, 1997, p. 731; ROSENTHAL, 2017, p. 147-148; BARGH \& MORSELLA, 2008), pois essa visão está comprometida com uma teoria disposicional do inconsciente (cf. DESCARTES, Respostas às quartas objeções [AT, VII, p. 246; AT, IX, p. 190];37 SEARLE, 1992, p. 161; SEARLE, 1997, p. 231), teoria que padece de diversos problemas sérios (cf. ROSENTHAL, 1986, p.

\footnotetext{
${ }^{34}$ Em sua obra Psicologia do ponto de vista empírico, Brentano procurou refutar os argumentos que ele identificou na literatura pertinente a favor da existência de fenômenos mentais inconscientes. Cf. Brentano (1924, p. 147-148); Brentano (1995, p. 105).

${ }^{35}$ Sartre considerava que "a existência de um fenômeno psíquico e o sentido que ele tem para a consciência são uma coisa só” (SARTRE, 1996, p. 36), posicionamento que, evidentemente, o obrigava a "rejeitar inteiramente a existência de um inconsciente" (Ibid., p. 36, nota $\mathrm{n}^{\circ} 13$ ). Sobre as perspectivas de Brentano e Sartre a respeito da consciência, cf. PRATA (2016).

36 Embora alegue divergir da perspectiva cartesiana (cf. SEARLE, 1992, p. 13-14; SEARLE, 1997, p. 24-25; SEARLE, 2004, p. 13), John Searle defende abertamente a tese de que "todas as outras noções mentais - como intencionalidade, subjetividade, causação mental, inteligência, etc. - só podem ser plenamente compreendidas como mentais por meio de suas relações com a consciência" (SEARLE, 1992, p. 84; SEARLE, 1997, p. 125-126).

37 Esse texto não está disponível na edição brasileira consultada para a redação do presente trabalho.
} 
342; ROSENTHAL, 1997, p. 732; ROSENTHAL, 2017, p. 149; PRATA, 2018, p. 51520).

Nesse sentido, uma teoria segundo a qual os fenômenos mentais existem independentemente de nossa consciência deles (cf. ARMSTRONG, 1968, p. 114) oferece um quadro teórico claro, dentro do qual podemos compreender o estatuto dos fenômenos mentais inconscientes em nossa vida mental.

Todavia, as concepções perceptivas da consciência enfrentam as suas próprias dificuldades (cf. ROSENTHAL, 1997, p. 739-740; ROSENTHAL, 2017, p. 163-164; VAN GULICK, 2012, p. 48). E, considerando a perspectiva adotada no presente trabalho, torna-se importante ressaltar que a maneira como Armstrong entende o inconsciente padece de algumas deficiências, pois uma vez que ele atribui à consciência um incremento das capacidades mentais, os fenômenos inconscientes aparecem em sua teoria de uma maneira distorcida, como se eles fossem muito menos poderosos do que eles realmente são.

O ponto é que ao pensar a consciência como responsável por uma integração de diversos processos mentais, integração que os tornaria mais sofisticados e eficientes, Armstrong sugere que os fenômenos mentais inconscientes possuem apenas capacidades bastante limitadas. Por exemplo, ele defende que a capacidade de solução de problemas depende da capacidade de pensar conscientemente sobre as diversas respostas possíveis, e da capacidade de escolher conscientemente a resposta a um problema que melhor se adéqua aos próprios objetivos, de modo que o animal capaz de resolver problemas mentalmente precisa ter ciência dos estados mentais relevantes (cf. ARMSTRONG, 1968, p. 163; ROSENTHAL, 2008b, p. 831).

O problema é que, se uma visão como essa estava em consonância com a perspectiva que, até algum tempo atrás, era predominante na psicologia cognitiva (cf., GREENWALD, 1992; LOFTUS \& KLINGER, 1992), tal visão, simplesmente, não resiste aos resultados de estudos mais recentes. Bargh \& Morsella (2008, p. 73) enfatizam que, diferente da psicologia cognitiva, as pesquisas em psicologia social, ao longo dos últimos 30 anos, consolidaram o ponto de vista de que a mente inconsciente é uma influência constante e poderosa sobre os processos mentais superiores.

O psicólogo holandês Ap Dijksterhuis (2004, p. 587) chama a atenção para o fato de que a atividade mental consciente tem uma capacidade relativamente baixa de processamento de informação (algo em torno de 40 a 60 bits por segundo, o equivalente a uma pequena sentença linguística), e destaca que os resultados de diversos estudos empíricos, realizados desde a década de 1990, mostram que a atividade consciente tem capacidades reduzidas para a solução de problemas. E ele próprio realizou um conjunto de experimentos sobre a tomada de decisões que reforçam essa conclusão. De acordo com ele:

Pensamento inconsciente melhorou a qualidade das decisões. Quando os sujeitos foram confrontados com decisões complexas, alguns minutos de distração, durante os quais eles puderam se engajar em pensamento inconsciente - mas não em pensamento consciente - levaram a decisões superiores se comparadas a 
circunstâncias nas quais os sujeitos não puderam se engajar em pensamento inconsciente, ou a circunstâncias nas quais eles se engajaram em pensamento consciente. (DIJKSTERHUIS, 2004, p. 596).

Portanto, a despeito de seus méritos para a elucidação do fenômeno da consciência, e para a articulação de uma concepção do inconsciente, a teoria de David Armstrong não estava à altura do verdadeiro papel dos fenômenos mentais inconscientes em nossa vida psicológica.

\section{REFERÊNCIAS}

ADAM, Charles; TANNERY, Paul. (Eds.). Ouvres de Descartes - Meditationes de prima philosophia. Paris: Vrin, 1996. (Vol. VII).

Ouvres de Descartes - Méditations et príncipes (traduction française). Paris: Vrin, 1996. (Vol. IX).

ARMSTRONG. David. A materialist theory of mind. London: Routledge \& Kegan Paul, 1968.

What is Consciousness? In: BLOCK, Ned; FLANAGAN, Owen; GÜZELDERE, Guven (Eds.). The nature of consciousness: philosophical debates. Cambridge, MA: MIT Press, 1997. p. 721-728.

BARGH, John A.; MORSELLA, Ezequiel. The unconscious mind. Perspectives on Psychological Science, v. 3, n. 1, p. 73-79, 2008.

BLOCK, Ned. On a confusion about a function of consciousness. In: BLOCK, Ned; FLANAGAN, Owen; GÜZELDERE, Guven (Eds.). The nature of consciousness: philosophical debates. Cambridge, MA: MIT Press, 1997. p. 375-415.

BRENTANO, Franz. Psychologie vom empirischen Standpunkt. 2.ed. Leipzig: Felix Meiner, 1924. Paul, 1995.

Psychology from an empirical standpoint. London: Routledge \& Kegan

CAROPRESSO, Fátima. Inconsciente, cérebro e consciência: reflexão sobre os fundamentos da metapsicologia freudiana. Scientiae Studia, v. 7, n. 2, p. 271-82, 2009.

CATALDO-MARIA, Thiago. M. S.; WINOGRAD, Monah. Freud e Brentano: mais que um flerte filosófico. Psico, v. 44, n. 1, p. 34-44, 2013.

CHALMERS, David. Facing up to the problem of consciousness. Journal of Consciousness Studies, v. 2, n. 3, p. 200-219, 1995.

DESCARTES, René. Discurso do método; Meditações; Objeções e Respostas; As Paixões da Alma; Cartas. 2.ed. São Paulo: Abril Cultural, 1979.

DIJKSTERHUIS, Ap. Think different: the merits of unconscious thought in preference development and decision making. Journal of Personality and Social Psychology, v. 87, n. 5, p. 586-598, 2004. 
FREUD, Sigmund. Vorlesungen zur Einführung in die Psychoanalyse: Neue Folge der Vorlesungen zur Einführung in die Psychoanalyse. Frankfurt am Main: Fischer Taschenbuch Verlag, 1982.

GENNARO, Rocco J. Consciousness and Selfconsciousness: a defense of the higher order thought theory of consciousness. Amsterdam; Philadelphia: John Benjamins Publishing, 1996.

(Org.). Higher-order theories of consciousness: an anthology. Amsterdam; Philadelphia: John Benjamins Publishing, 2004.

GREENWALD, Anthony G. New look III: Unconscious cognition reclaimed. American Psychologist, v. 47, p. 766-779, 1992.

GÜZELDERE, Güven. Introduction - Many faces of consciousness: a field guide. In: BLOCK, Ned; FLANAGAN, Owen; GÜZELDERE, Guven (Eds.). The nature of consciousness: philosophical debates. Cambridge, MA: MIT Press, 1997. p. 01-67.

HABERMAS, Jürgen. Pensamento pós-metafísico. Rio de Janeiro: Tempo Brasileiro, 1990.

KEMMERLING, Andreas. Ideen des Ichs: Studien zur Philosophie Descartes'. Frankfurt am Main: Vittorio Klostermann, 2005.

KIM, Jaegwon. Philosophy of mind. Boulder: Westview Press, 1996.

KRIEGEL, Uriah. Consciousness and Self-consciousness. The Monist, v. 87, n. 2, p. 182-205, 2004.

Subjective consciousness: a self-representational theory. Oxford: Oxford University Press, 2009.

LOFTUS, Elizabeth F.; KLINGER, Mark R. Is the unconscious smart or dumb? American Psychologist, v. 47, p. 761-765, 1992.

PRATA, Tárik. A. A estrutura da autoconsciência na filosofia da mente de John Searle. Veritas, v. 62, n. 2, p. 428-452, 2017.

As perspectivas de Brentano e Sartre sobre a auto-referencialidade da consciência. Rapsódia, v. 10, p. 42-62, 2016.

Uma objeção à concepção disposicional dos fenômenos mentais inconscientes. Principia, v. 22, n. 3, p. 507-526, 2018.

ROSENTHAL, David. Two concepts of consciousness. Philosophical Studies, v. 49, p. 329-359, 1986.

ROSENTHAL, David. A theory of consciousness. In: BLOCK, Ned; FLANAGAN, Owen; GÜZELDERE, Guven (Eds.). The nature of consciousness: philosophical debates. Cambridge, MA: MIT Press, 1997. p. 729-753.

Higher-order theories of consciousness. In: McLAUGHLIN, Brian; BECKERMANN, Ansgar (Eds.). Oxford handbook of the philosophy of mind. Oxford: Oxford University Press, 2008a. p. 239-52. 
ROSENTHAL, David. Consciousness and its Function. Neuropsychologia, v. 46, p. 829-840, 2008b.

2017.. Uma teoria da consciência. Perspectiva Filosófica, v. 44, n. 2, p. 143-178,

RYLE, Gilbert. The concept of mind. Harmondworth: Penguin Books, 1970.

SARTRE, Jean-Paul. O imaginário: psicologia fenomenológica da imaginação. São Paulo: Editora Ática, 1996.

SCHELLENBACHER, Manfred. Sigmund Freud und Franz Brentano. E-Journal für Philosophie der Psychologie, v. 15, p. 01-07, 2011.

SEARLE, John R. The rediscovery of the mind. Cambridge MA: MIT Press, 1992. . A redescoberta da mente. São Paulo: Martins Fontes, 1997. Mind: a brief introduction. Oxford: Oxford University Press, 2004.

VAN GULICK, Robert. Higher-Order Global States (HOGS): an alternative higherorder model of consciousness. In: GENNARO, Rocco (Ed.). Higher-order theories of consciousness: an anthology. Amsterdam; Philadelphia: John Benjamins Publishing, 2004. p. 227-254.

. Consciência. Investigação Filosófica, v. E2, Artigo digital 2, 2012.

Recebido em: 08-03-2019

Aceito para publicação em: 08-07-19 